\title{
A Brief Discussion on the Factors Influencing the Formation of Subordinates' Followership
}

\author{
Yueqi Wang, Haomin Zhang \\ Shanghai University, Shanghai, China \\ Email: yqwang@163.com
}

How to cite this paper: Wang, Y.Q. and Zhang, H.M. (2018) A Brief Discussion on the Factors Influencing the Formation of Subordinates' Followership. Open Journal of Business and Management, 6, 707-713. https://doi.org/10.4236/ojbm.2018.63054

Received: June 28, 2018

Accepted: July 21, 2018

Published: July 24, 2018

Copyright $\odot 2018$ by authors and Scientific Research Publishing Inc. This work is licensed under the Creative Commons Attribution International License (CC BY 4.0).

http://creativecommons.org/licenses/by/4.0/

(c) (i) Open Access

\begin{abstract}
The following of subordinates to leaders includes not only the positive recognition of subordinates to leaders in subjective aspects, but also a series of practical actions of subordinates to support leaders. It is a new and important topic in employees' personal and organizational management practice to improve their followership. How to inspire Subordinates' followership is undoubtedly a question for leaders to consider. In some sense, leadership is the ability of a leader to inspire followers to follow. There are many factors that affect the ability to follow, and this paper discusses the psychological factors and leadership factors that influence the formation of subordinates' followership.
\end{abstract}

\section{Keywords}

Followership, Power, Inspire

\section{Introduction}

The composition of the followership is undoubtedly complex and diverse. But generally speaking, the followership is composed of two aspects: the subjective state and the behavior ability of followers. In terms of subjective state, it mainly refers to the positive personal characteristics of followers in the process of following, such as the positive and active working attitude, personal characteristics of integrity and loyalty, and enterprising spirit of not afraid of difficulties.

In terms of behavioral ability, it mainly refers to the ability of followers to work together with leaders, and colleagues in order to achieve organizational goals. To be specific, it mainly includes the insight of followers in finding problems, the thinking ability of seeking solutions to problems, the executive ability to complete tasks assigned by leaders, and the ability to handle interpersonal relations. 
Taking the behavior ability and subjective state which constitute the followership as the vertical and horizontal coordinate axis, thus an ideal range diagram for the followership can be constructed. The positive direction of the subjective state represents the positive factors such as active, enterprising, brave and loyal followers, while the negative direction represents the negative factors such as passivity, cowardice, avoidance and betrayal of followers. The positive direction of the behavior ability axis represents the positive factors of insight, thinking, execution and communication. When subordinates are passive, betray or even opposed in their subjective states, the stronger their ability is, the greater the reverse action is to leaders. When subordinates are positive, enterprising, loyal and intelligent in their subjective state, their behavioral ability and subjective state will produce different followerships at different stages: when the subjective state and behavior ability of followers are lower than the limits that leaders themselves can tolerate in these two aspects, they are seen by leaders as weak followers; when the subjective state and behavior ability of followers exceed the upper limit of the leaders themselves in these two aspects, that is, the comprehensive strength of followers exceeds the strength of leaders, followers become potential replacements for leaders .

Therefore, the ideal range of the followership is the subjective state and behavior ability of followers is between the upper and lower limits of the leader's subjective state and behavior ability, which is shown in Figure 1 [1].

\section{Factors That Influence Subordinates' Followership}

\subsection{Psychological Factors}

Psychological factors include psychological factors which affect the formation of the individual's followership and group followership.

\subsubsection{Psychological Factors for the Formation of the Individual's Followership}

The "implicit following" theory in psychology is very instructive for us to understand the formation and promotion of individual's followership. The word "implicit" in "implicit following" is a series of preconceived assumptions and expectations in people's minds. The study found that leaders internalize some certain "implicit following" in their daily interactions with their subordinates and form a relatively fixed evaluation standard.

Moreover, leaders will constantly match and contrast the inner picture (ideal subordinates) formed by their judgments and expectations on all aspects of their subordinates with the actual performance of their subordinates intentionally or unintentionally. If the two match well, the leader will make a series of positive and affirmative actions to them. For example, they may give subordinates more trust, better platforms and greater motivations. So a positive interaction will be formed between leaders and subordinates. However, even when the "implicit following" of the leader is highly consistent with the actual following behavior of the subordinate, here is still limit to the positive interaction between leaders and 


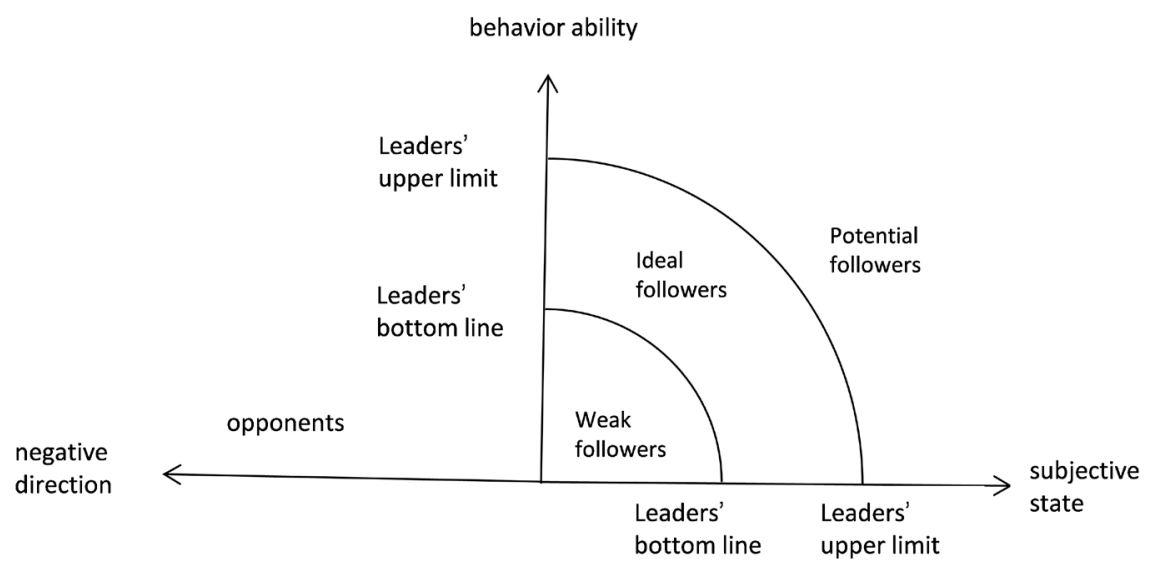

Figure 1. The ideal range of the followership.

subordinates. Because the positive interaction between leaders and subordinates depends not only on the actual authorization of leaders, but also on the psychological authorization that followers can feel (Subordinates' cognition of work value and self-ability). Faced with the tasks assigned by the leaders, the hearts of subordinates can be motivated when they can have a sense of value and success [2].

\subsubsection{Psychological Factors for the Formation of Group Followership} Competition and cooperation are the basic forms of mutual influence among subordinates. Competition can stimulate the morale and potential of each individual in the group, while cooperation can help subordinates form a better team spirit. Imitation is learning the behavior of others in a group, either to satisfy the curiosity or to adapt to the surrounding environment. Conformity psychology mainly stems from the fact that subordinates do not want to be isolated and unsociable, so as to keep consistent with the majority of the group members. Conformity produces an invisible group norm. In work, if the leader has enough ability and experience to deal with the psychology of the subordinate group, the group norms and group synergy among subordinates will be formed. Subordinates in a harmonious and comfortable environment will give full play to their potential and yield twice the result with half the effort. Therefore, the ideal effect is formed that the group followership is greater than the sum of the individual followership within the group. If the leader ignores the psychological guidance and integration of the subordinate group, then the contradictions among subordinates could not be resolved in time, which leads to tension in interpersonal relations, thus a lonely and indifferent working atmosphere will be formed. Of course, an ideal group followership will be difficult to form [3].

\subsection{Factors of Leaders}

\subsubsection{The Quality and Ability of a Leader}

This is about the personal qualities of a leader, that is, the individual ability of the leader. It is embodied in a capacity to shoulder heavy expectations and an 
ability to command obedience from the leader's own influence. Due to the unique temperament and attraction of such a leader, employees are willing to follow the leader to achieve the goals of the enterprise. Part of this leadership temperament and charismatic personality comes from innate enjoyment, and not everyone has it. But that doesn't mean it can't be cultivated. Other people can also pay attention to every person who has a relationship with them and work hard to turn it into a charm.

Among them, professional quality is also an important part of personal qualities. A leader's expertise (knowledge) is acquired through systematic and professional learning. This ability comes from the use of expertise and specific information to understand and handle complex situations. Expertise is related to the education, training and experience of the leader, which makes the leader an expert in some areas [4].

\subsubsection{The Will and Purpose of a Leader}

First of all, the primary goal of a leader is to align his own will with the will of the group and thereby shape the will of the group. Enterprise value should reflect the common dream, common norms, common expectation and common purpose of the group. Only when the leaders take everyone's will as the criterion, can people be willing to accept pain and frustration, and are willing to fight for the value of the enterprise. But over time, corporate values and shared visions decay, and those values are no longer attractive, so the change in value is urgent. The main reason why some successful companies can keep their value standards alive is that they can adapt to changes in the environment, and they are able to continually re-establish values that are dynamic and attractive. Secondly, besides considering the interests of enterprises and employees, private interests will also be considered when leaders are making decisions. When the leader damages the interests of his followers for the sake of his personal interests, the followership will gradually become weaken or even disappear. Followers follow the leader based on the belief that the leader will bring him the satisfaction of needs. Once such needs are destroyed, it will inevitably lead to the decline of followership [5].

\subsubsection{Leaders' Motivational Techniques}

Leaders need technical skills and administrative skills. Technical skills refer to the ability of leaders to develop and apply certain methods and technologies that are relevant to their work. In addition, leaders should comprehensively understand and be familiar with the various technical activities undertaken by its departments and relationships with other departments. This technology is inseparable from the education, experience, training and learning that leaders receive. Administrative technology refers to leaders creating groups or organizations, making plans, making decisions, implementing controls, and giving feedback on their work, and the ability to motivate and communicate with employees to achieve organizational goals or leadership goals [6].

Leadership is an elusive quality that motivates others to act. This quality 
enables a supervisor to make others accept his leadership voluntarily. Great leaders seem to have a special knack for making others willing to follow them and do what they want to do. This requires the ability of a leader to understand the needs of his followers. Leaders should use different incentives depending on the individual's circumstances in order to improve work efficiency, which in short, is motivation. The art of leadership is to give full play to each individual's personality according to the differences of their personalities. It is because of personality that a person is a person. The so-called person is only the existence of personality. This requires leaders to analyze followers' motivations, desires, needs, hopes, and similar forces, that's why people are willing to work [7].

\section{Effective Ways to Increase Followership}

\subsection{Activate the Individual Followership, and at the Same Time Cannot Ignore the Cultivation of the Group Followership}

Leaders should establish a positive "implicit following". For one thing, leaders should try to find the good in their subordinates. In this way, subordinates can give back their leaders' trust and appreciation with positive followership behaviors. On the other hand, leaders should not ignore the psychology of the weak followers while focusing on supporting the followers that meet his expectations in order to change a weak follower into an ideal follower. At the same time, in order to cultivate the followership of the group, the leader himself must master some certain social psychology knowledge. Leaders should build a positive team culture and cultivate a good team style.

\subsection{Leaders Should Establish a Positive Implicit Following}

For one thing, leaders should try to find the advantages in their subordinates. According to the enlightenment of the theory of implicit following, leaders should try to find the advantages in their subordinates with confidence and appreciation. On the other hand, the leader should not ignore the psychology of caring for the weak followers while focusing on supporting the followers that meet his expectations. Every subordinate should feel the attention and care from the leader so as to make a weak follower into an ideal follower. At the same time, leaders should be good at identifying and focusing on developing influential backbone followers. Leaders should strengthen education guidance to key subordinates, empower them psychologically, inspire their sense of responsibility, and enable them to influence more people to follow their leaders.

\subsection{The Excellent Qualities of a Leader Is the Driving Force That Motivates His Subordinates to Follow Him}

It can be seen from the above analysis of the ideal range of the followership that the better a leader is at subjectivity or behavior, the more able he is to bring together more and better followers. It is the scientific and reasonable "implicit following" of leaders that promotes the benign interaction between leaders and 
subordinates and triggers the constant escalation of the followers. When faced with subordinates, if the leader is depressed and does not think of progress, it will inevitably lead to excellent subordinates do not see hope. At the same time, it will cause the irresponsible subordinates to muddle along. If the leader is lazy and timid in his actions, he will make his subordinates complain and even arouse their antagonism. Therefore, leaders should improve themselves in both subjective and behavioral aspects. In terms of the subjective state, the leader should have integrity and loyalty, the psychological quality of being fearless in the face of danger, and a more active working attitude than his subordinates. In terms of behavioral ability, leaders should have a stronger ability to unite subordinates and motivate subordinates to actively achieve organizational goals. It mainly includes keen insight into potential problems, clear thinking to find solutions to problems, and good interpersonal skills [8].

\subsection{The Role of Informal Communication Is Irreplaceable}

Leaders should not be above other, but should pay attention to the practical difficulties in the work and life of their subordinates, and should show a strong affinity appropriately. If the subordinates feel the meticulous care, consideration and kindness from the leader, they will follow the leader sincerely. Therefore, to cultivate followership, leaders should neither wait for subordinates to communicate with them, nor only communicate with them in the workplace. They should take the initiative to have a moderate amount of informal communication with subordinates after work [9].

For some of the more passive subordinates, especially workplace newbies and introverts, leaders need to be proactive to communicate with them. For example, leaders can talk informally about work and life after work and actively help subordinates remove the psychological burden when facing the leadership. Leaders can also expand the informal communication channels with subordinates through some group cultural and recreational activities. In recreational activities with loose atmosphere and lively forms, leaders and subordinates are easy to let go of all kinds of inhibitions and scruples, show true temperament, express true ideas and achieve true communication [10].

\section{Conclusion}

Leaders should try to find out the advantages of their subordinates and use them for their talents. In addition, the excellent qualities of the leader are the source of energy to activate the followership. In the formation of group followership, the group has the psychological characteristics of imitation, conformity and infection, while the leader is the head of the team and the subject of imitation. And this kind of imitation is widespread, and can even develop into the collective imitation of subordinate groups, give talented subordinates enough respect, trust and motivation and let them feel empowered. Giving the talented subordinate tasks and expectations that match their abilities can often inspire a strong sense 
of confidence and effectiveness, and develop their recognition of their leader, which leads to positive following behaviors. Leaders should also combine informal communication and other means to promote the close relationship between leaders and subordinates, so as to improve the followers of subordinates [11].

\section{Conflicts of Interest}

The authors declare no conflicts of interest regarding the publication of this paper.

\section{References}

[1] Tang, L. and Yang, W.G. (2015) Research on the Followership and Its Theoretical Framework: Overview and Prospect. Journal of Xuehai, 5, 143-149.

[2] Adams, J.S. (1963) Towards an Understanding of Inequity. Journal of Abnormal \& Social Psychology, 67, 422-436. https://doi.org/10.1037/h0040968

[3] Arogundade, O.T. and Arogundade, A.B. (2015) Psychological Empowerment in the Workplace: Implications for Employees' Career Satisfaction. North American Journal of Psychology, 17, 27-36.

[4] Blau, P.M. (1968) The Hierarchy of Authority in Organizations. American Journal of Sociology, 73, 453-764. https://doi.org/10.1086/224506

[5] Derler, A. and Weibler, J. (2014) The Ideal Employee: Context and Leaders' Implicit Follower Theories. Leadership \& Organization Development Journal, 35, 386-409. https://doi.org/10.1108/LODJ-12-2012-0158

[6] Junker, N.M. and van Dick, R. (2014) Implicit Theories in Organizational Settings: A Systematic Review and Research Agenda of Implicit Leadership and Followership Theories. The Leadership Quarterly, 25, 1154-1173.

https://doi.org/10.1016/j.leaqua.2014.09.002

[7] Burak, O.C. and Bashshur, M.R. (2013) Followership, Leadership and Social Influence. The Leadership Quarterly, 6, 18.

[8] Uhl-Bien, M., Riggio, R.E., Lowe, K.B. and Carsten, M.K. (2013) Followership Theory: A Review and Research Agenda. The Leadership Quarterly, 6, 30.

[9] Shalit, A., Popper, M. and Zakay, D. (2010) Followers' Attachment Styles and Their Preference for Social or for Personal Charismatic Leaders. Leadership \& Organization Development Journal, 5, 9. https://doi.org/10.1108/01437731011056461

[10] Thomas, S.Y. (2010) What Do You Think of Followers? Examining the Content, Structure, and Consequences of Implicit Followership Theories. Organizational Behavior and Human Decision Processes, 2, 80.

[11] Grant, A.M. and Ashford, S.J. (2008) The Dynamics of Proactivity at Work. Research in Organizational Behavior, 2, 30. https://doi.org/10.1016/j.riob.2008.04.002 